\title{
ORIGINAL CONTRIBUTION \\ Comparison of Fatigue Analysis Results in the Frequency Domain using PSD data and specific load
}

\author{
Joon Jang ${ }^{1}$, Jae Myung Cho ${ }^{2}$, Won Woong Lee ${ }^{3}$, Woo Chun Choi ${ }^{4}$ \\ 1, 4 School of Mechanical Engineering, Korea University, Seoul, Korea \\ 2, 3 HANWHA Systems, Gyeonggi-do, Korea
}

\begin{abstract}
This study investigated the axial sensitivity of the aircraft structure to fatigue. Fatigue analysis for an aircraft needs to be done during a design stage to prevent fatigue failure during operation. Fatigue analysis can be done in a time domain or a frequency domain, and frequency domain analysis is more frequently used. Frequency domain analysis for an aircraft normally uses PSD data translated from the vibration experienced for its whole lifetime. If vibration information is insufficient in the PSD, it is supplemented by adding specific loads. In this study, the analysis was done using the PSD data with $\mathbf{7}$ different additional loads. The life was sensitive to the magnitude and direction of the load, and some loads increase the life. It was found that the aircraft structure is safe from fatigue failure. Since the fatigue test has not yet been carried out, further testing should be done. Also, further study will investigate how to quantify the sensitivity ratio of direction and magnitude of loads under various conditions.
\end{abstract}

Index Terms - Frequency Domain, Fatigue Analysis, PSD, POD Structure

Received: 2 April 2019; Accepted: 3 May 2019; Published: 26 June 2019

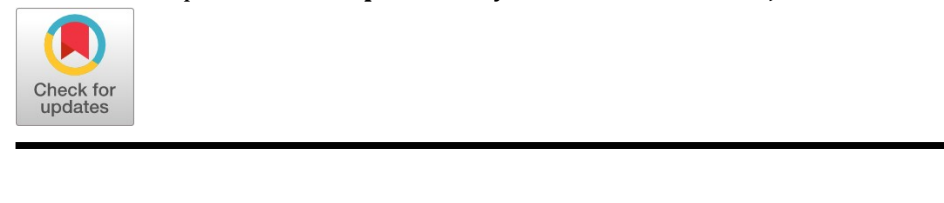

\section{INTRODUCTION}

It is important to predict fatigue failure at the design stage of an aircraft. Because if fatigue failure occurs during operation of an aircraft, a serious human injury will occur. Fatigue analysis is done to prevent fatigue failure. Although fatigue analysis can be done in a time domain or a frequency domain, a frequency domain analysis is more frequently used due to limited resource. Aircraft frequency domain fatigue analysis uses PSD data based on measurement or prediction through the vibration of its whole lifetime. In MIL-STD-810G, PSD data is calculated and classified according to the aircraft type [1].

There may be a case where the vibration for the reference of the PSD data is insufficient for use. For example, for the PSD of a truck, the vibration PSD data of a truck running on a highway and the PSD data of a truck running on an unpaved road have different values. While it is best to use the PSD of an unpaved road when designing a truck to run on unpaved roads, there may be no PSD data available for the unpaved road. In this case, the additional load is added to highway PSD data and used for fatigue analysis.

Since the PSD data is essential for predicting the life of parts, various studies have been conducted on PSD data. There was a study comparing time domain fatigue analysis with frequency domain fatigue analysis (using PSD) using a test specimen[2]. Theoretical background to find equivalent fatigue load in the time domain and frequency domain was described, and fatigue loads were obtained by applying uniaxial and multiaxial loads to the cantilever beams [3]. Various fatigue damage models ap-

\footnotetext{
${ }^{*}$ Corresponding author: Woo Chun Choi

${ }^{\dagger}$ Email: wcchoi@korea.ac.kr
}

plied to fatigue damage analysis of a broadband response spectrum were introduced, and numerical comparative studies for selecting fatigue damage models suitable for riser fatigue analysis were conducted $[4,5]$ Eight types of PSD analysis methods were introduced, and their accuracies and errors were analyzed [6, 7]. Four types of PSD analysis methods used for the frequency domain fatigue analysis were compared, and the fatigue life of the aircraft was predicted using Dirlik and Benasciutti-Tovo methods [8] Time domain and frequency domain fatigue analysis were performed for a F-5 plane and compared [9]. A gearbox housings of high-speed trains were analyzed by time domain, frequency domain, and time-frequency domain analysis [10]. A general methodology to predict the fatigue life of the Package-on-Package under random vibration loading by means of vibration tests and finite element simulation was presented $[11,12]$. The relationship between mean stress effect and two kinds of frequency domain fatigue life was introduced. Also, a mean stress correction model was proposed [13].

Most studies have dealt only with methods of PSD analysis $[14,15$, $16,17,18,19,20,21]$. However, since there is insufficient PSD data in many cases, study to compensate for the insufficient PSD data is also important. In this study, the method of aircraft fatigue analysis with insufficient PSD data is investigated. The PSD data used in the study consists of the vibration generated only in a general flight. Therefore, there is no data about the vibration that occurs during special missions. Therefore, seven types of load caused by special missions are added to the general PSD data to predict the fatigue life and the fatigue lives are compared with the fatigue life predicted with only the PSD data. 


\section{FATIGUE ANALYSIS PROCESS}

The fatigue life is estimated using FRF and PSD. After obtaining FRF that has a dynamic characteristic of the object to be analyzed, the PSD is probabilistically analyzed to obtain PDF of the stress range distribution, and then rainflow counting is performed. After that, the life is predicted by the counted cycles, Miner's rule and S-N curve. In this case, Miner's rule assumes that fatigue failure is caused by an accumulation of damages when the stress over the fatigue limit is repeatedly applied to the structure. Miner's rule is expressed as Eq. 1[22].

$$
\sum D_{i}=\frac{n_{1}}{N_{1}}+\frac{n_{2}}{N_{2}}+\frac{n_{3}}{N_{3}}+\ldots+\frac{n_{i}}{N_{i}} \geq 1
$$

where, $n_{i}$ is repeat number at $\mathrm{Si}$ stress, $N_{i}$ is fatigue life at $\mathrm{Si}$ stress. $D_{i}$ means damage, and fatigue failure occurs when the sum of damages is over 1 .

Depending on the analysis method of PSD, the value of PDF will change and rainflow countings using PDF will be different. Therefore, according to the analysis method of PSD, fatigue life will be changed. Therefore, it is important to analyze the PSD using an appropriate analysis method. In this study, the PSD data is analyzed by Steinberg method. Steinberg method is often used because of its simplicity and is primarily used for electronic equipment. And it assumes that the cumulative fatigue damage is calculated assuming that the stress amplitude response at a given position has a Gaussian distribution having $68.3 \%$ time at 1 sigma, $27.1 \%$ time at 2 sigma, and $4.3 \%$ time at 3 sigma. It also shows conservative results compared to other methods $[23,24]$.

\section{FREQUENCY DOMAIN FATIGUE ANALYSIS}

The study is performed by frequency domain fatigue analysis. FRF is estimated by Modal and Harmonic analysis of ANSYS workbench, and fatigue analysis is performed based on FRF, PSD and load using Ncode tool. In this study, a POD structure attached to the bottom of the aircraft wing is considered important, and thus the POD structure is analyzed rather than the whole aircraft model. The FEM model of the POD structure used in analysis consists of 1,255,358 nodes and 733,659 elements. Material properties are shown in Table I, and the POD model is similar to Fig. 1. Most parts are made of Al6061. Although the interior contains sensors and electronic equipment, the internal parts are replaced by a point mass because the purpose of the study is fatigue analysis of the frame structure. The POD structure consists of the sum of parts, and the results of fatigue analysis vary depending on how the connection of parts is implemented. Using solid elements is the most accurate, but takes the longest analysis time. Therefore, the fastening parts between the frames are implemented using solid elements in the form of a screw, and the remaining fastening parts such as frame-to-case or case-to-case connection are implemented using beam elements in this study.

PSD data similar to Fig. 2 was used [1]. Because the PSD data used was based on general flight, loads received when aircraft performs special missions are classified into seven conditions and added to the PSD data. Seven classified loads are shown in Table II. In this time, X-axis is fore direction, $\mathrm{Y}$-axis is lateral direction, and Z-axis is vertical direction $[25,26,27,28]$.

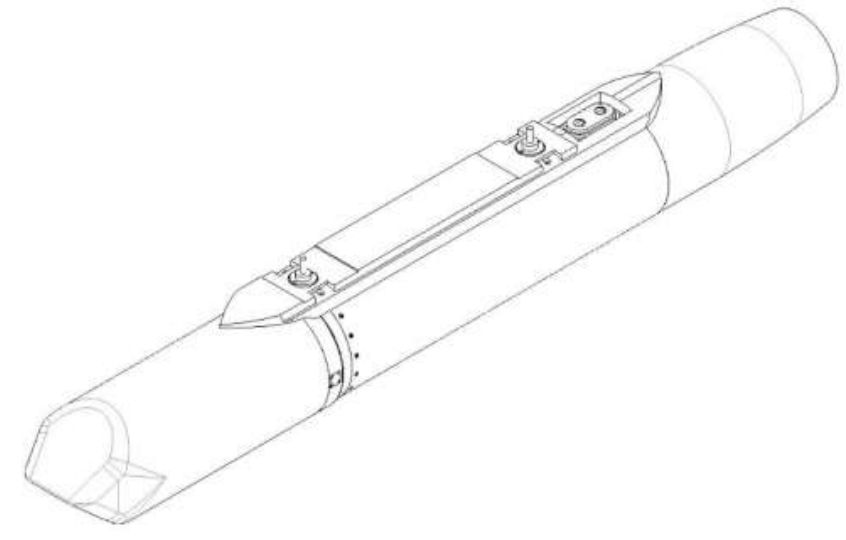

Fig. 1. POD structure

TABLE I

MATERIAL PROPERTY

\begin{tabular}{llll}
\hline \hline Material & Ultimate Strength & Poisson's ratio & Density (g/cm3) \\
\hline PH13-Steel & $1105 \mathrm{MPa}$ & 0.3 & 7.8 \\
17-4PH Steel & $1158 \mathrm{MPa}$ & 0.3 & 7.75 \\
SUS304 & $310 \mathrm{MPa}$ & 0.33 & 2.85 \\
AL6061 & $520 \mathrm{MPa}$ & 0.3 & 7.85 \\
\hline \hline
\end{tabular}

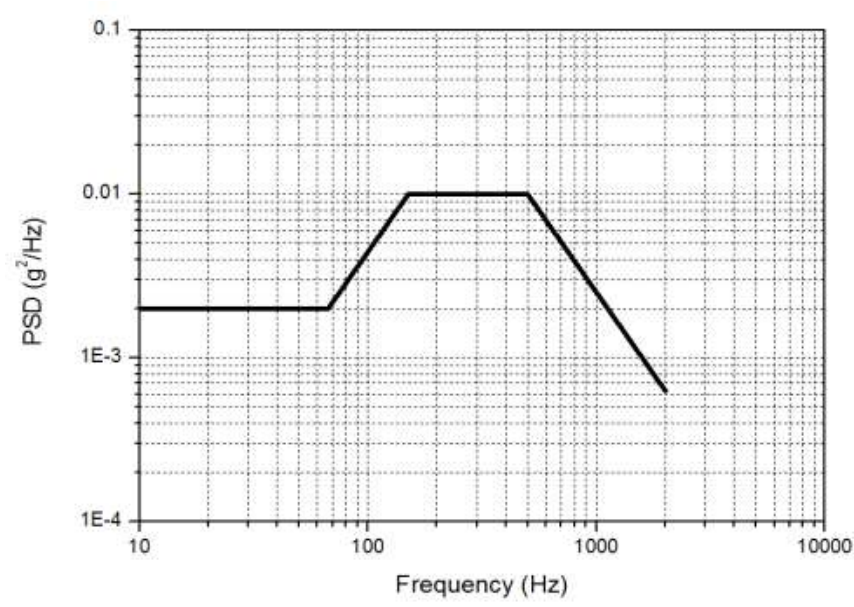

Fig. 2. PSD profile

TABLE II

LOAD CONDITION

\begin{tabular}{llllllll}
\hline \hline No. & 1 & 2 & 3 & 4 & 5 & 6 & 7 \\
\hline $\mathrm{X}(\mathrm{g})$ & 0 & 0 & 0 & 0 & 5 & 4 & -3 \\
$\mathrm{Y}(\mathrm{g})$ & 0 & 0 & 2 & 2 & 0 & 0 & 0 \\
$\mathrm{Z}(\mathrm{g})$ & 10 & -5 & 7 & 1 & 2 & 10 & 10 \\
\hline \hline
\end{tabular}




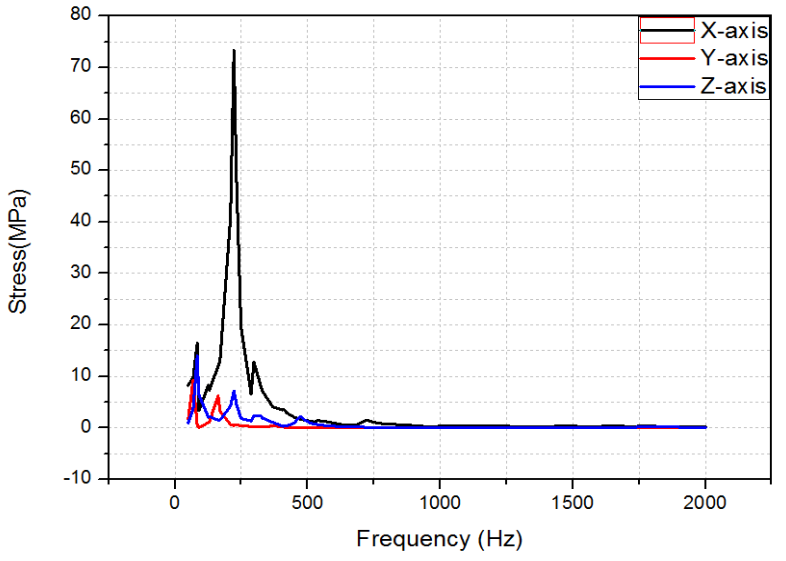

Fig. 3. FRF of POD structure

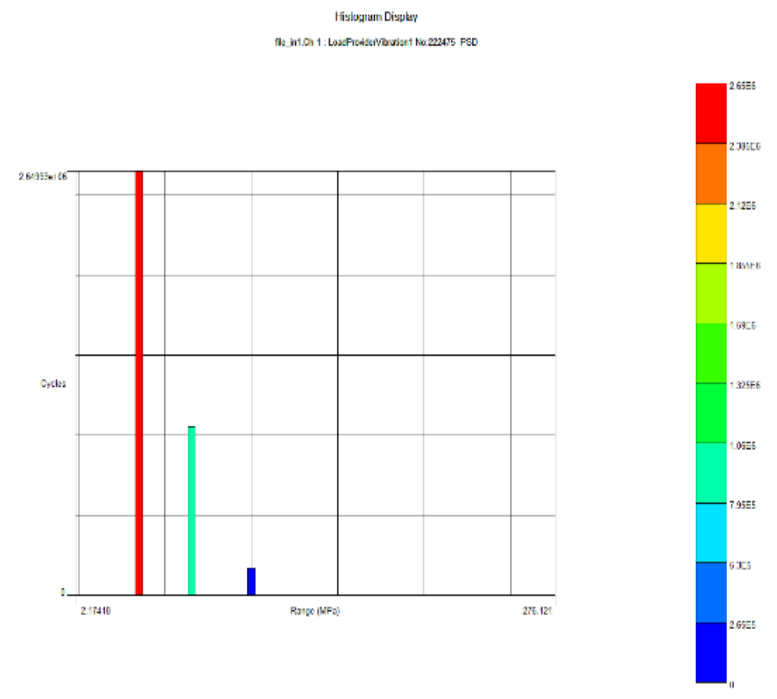

Fig. 4. Result of PSD condition a) Cycle Histogram. b) Damage Histogram

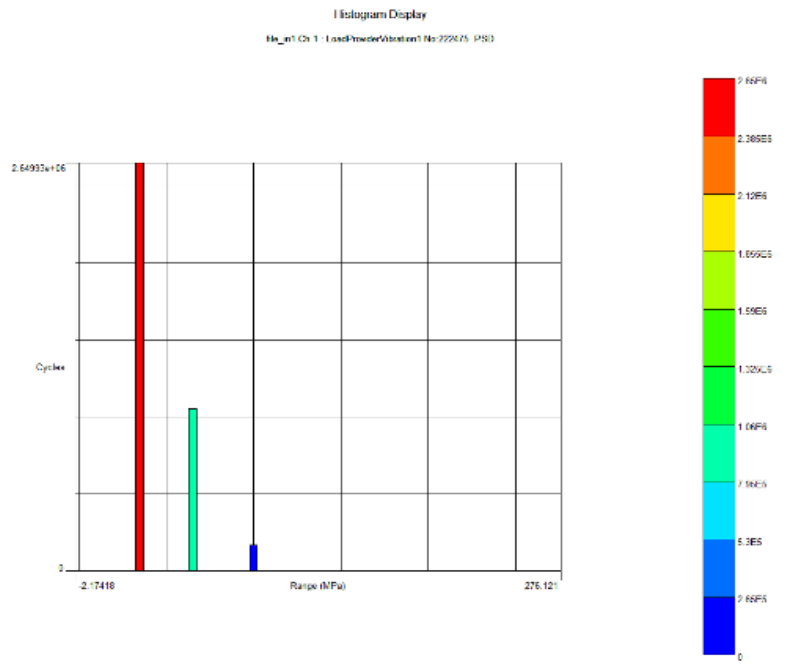

\section{RESULTS}

FRF of weak points in the POD structure is shown in Fig. 3. When PSD data is estimated only and when the load for each case is added, the weakest point appears in the binding points of the POD adaptor. To compare cycles and damage with and without additional loads, the cycle histogram and damage histogram using the PSD data only are shown in Fig. 4, and the cycle histogram and damage histogram at PSD +1 condition are shown in Fig. 5.

The result with only PSD data and results with adding load for each case are shown in Table III. The life is higher in order of PSD + 5, PSD + 6, $\mathrm{PSD}+2, \mathrm{PSD}+4, \mathrm{PSD}+1, \mathrm{PSD}+3$, and PSD + 7. Among these, the PSD + 5 and PSD +6 conditions have higher lives than the PSD data only.
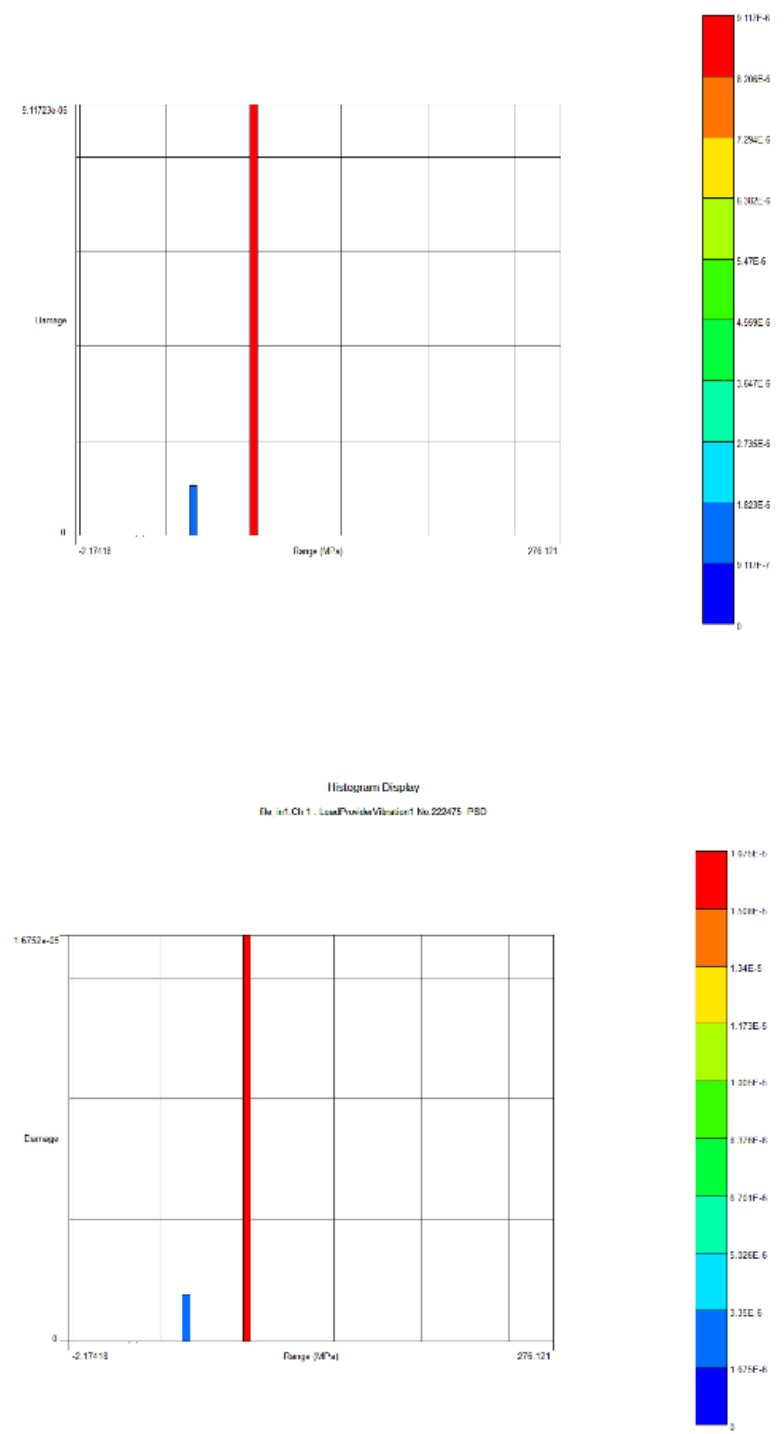

Fig. 5. Result of PSD+1 condition a) Cycle Histogram. b) Damage Histogram 
TABLE III

LIFE OF THE WEAKEST NODE IN POD STRUCTURE

\begin{tabular}{llll}
\hline \hline Condition & RMS stress [MPa] & Mean stress [MPa] & Life \\
\hline PSD & 31.02 & 11.28 & 4.705 \\
PSD + 1 & 31.02 & 29.2 & 2.561 \\
PSD + 2 & 29.95 & 20.77 & 4.285 \\
PSD + 3 & 31.02 & 34.2 & 2.146 \\
PSD + 4 & 31.02 & 19.8 & 3.539 \\
PSD + 5 & 28.93 & 19.46 & 8.661 \\
PSD + 6 & 31.02 & 10.99 & 4.75 \\
PSD + 7 & 31.02 & 41.68 & 1.638 \\
\hline \hline
\end{tabular}

\section{DISCUSSION}

Analyzing the FRF graph, the POD structure has high sensitivity on the X-axis and similar sensitivity on the $\mathrm{Y}$-axis or Z-axis in the entire frequency range. The X-axis is most sensitive at about $250 \mathrm{~Hz}$, and the $\mathrm{Y}$ axis and Z-axis are most sensitive below $100 \mathrm{~Hz}$. Also, when only vibration below $100 \mathrm{~Hz}$ is applied, the sensitivities between the $\mathrm{X}$-axis, Y-axis, and $\mathrm{Z}$-axis are similar.

As shown in the cycle histogram, the stresses applied to the nodes are classified into three types of stress bars because the Steinberg method is used. Also, low stress has a high number of cycles, and high stress has a low number of cycles. However, as shown in the damage histogram, the first stress bar with the highest cycle in the cycle histogram does not affect the life, while the third stress bar with the lowest cycle has the largest effect on the life. This phenomenon occurs because the first stress bar is lower than the fatigue limit of Al6061. When the additional load is applied, some of the stresses in the first stress bar move to the second stress bar. Since the second stress bar is greater than the fatigue limit, it affects the life. Likewise, some of the stresses in the second stress bar move to the third stress bar, and they affect the life.

Analysis results obtained when loads are added, conditions with the lowest life are 1, 3 and 7 conditions. These conditions are common conditions in which positive $\mathrm{Z}$-axis force is $7 \mathrm{~g}$ to $10 \mathrm{~g}$. From this, it can be seen that the force in the positive Z-axis direction has a big influence on life. As seen in condition 2, the force in the negative Z-axis direction doesn't have a big effect. On the other hand, in case of condition 6, the effect of the life is similar even though the force in the positive $\mathrm{Z}$-axis is $10 \mathrm{~g}$. It is found that the force in the positive X-axis direction is influential. As in condition 6, condition 5 with the positive $\mathrm{X}$-axis force results in double of the existing life, which seems to have a positive effect on the life for the positive X-axis force. Therefore, in the case of condition 6 , the influence of force in the positive $\mathrm{X}$-axis direction and the force in the $\mathrm{Z}$-axis direction are cancelled, and the results are similar to the existing life. Conversely, the negative $\mathrm{X}$-axis force appears to have a negative effect on life, as shown by the comparison of conditions 1 and 7 . In the case of the 3 conditions, compared with 1 condition, the force in the positive $\mathrm{Z}$-axis direction is decreased, and the force in the positive Y-axis direction is increased, and the life is decreased than that of 1 condition. It can be seen that the force in the positive Y-axis direction has a negative effect on the life.

In summary, most loads have a negative effect on life, but positive $\mathrm{X}$-axis direction loads have a positive effect on life. In addition, the sensitivity is largest in positive $\mathrm{X}$-axis, followed by $\mathrm{Y}$-axis and Z-axis. This is consistent with FRF results. These results indicate that the more vertical and horizontal maneuver during the mission of aircraft reduces the life and the more deceleration maneuver increases the life. In general, additional loads are expected to have a negative effect on the life, but some additional loads can actually have a positive effect on the life. In addition, the POD structure used in this study satisfies the minimum required life under all conditions.

\section{CONCLUSION AND IMPLICATIONS}

The fatigue analysis result using PSD data only and the fatigue analysis results using seven additional loads were compared in a frequency domain. The following conclusions were drawn in this study.

- The POD structure is susceptible to the $250 \mathrm{~Hz}$ vibration in the Xaxis direction.

- Since the majority of the stresses counted are below the fatigue limit of Al6061, they do not affect the life.

- When the additional load is applied, some of the stresses below the fatigue limit exceed the fatigue limit, and they affect the life.

- Positive X-axis direction load had a positive effect on the life, but other direction loads had a negative effect on the life.

- Life had load sensitivity in the order of X-axis, Y-axis and Z-axis, and FRF analysis showed a similar result.

- The POD structure satisfied the minimum required life under all conditions.

In this study, fatigue life is predicted successfully by insufficient PSD data with the additional load. However, since the fatigue test has not yet been carried out, further testing should be done. Also, further study will investigate how to quantify the sensitivity ratio of direction and magnitude of loads under various conditions.

\section{ACKNOWLEDGEMENT}

This work was supported by a grant-in-aid of HANWHA SYSTEMS.

\section{Declaration of Competing Interest}

The authors declare that there is no conflict of interest.

\section{References}

[1] MIL-STD-810G. (2008) Department of defence test method standards. [Online]. Available: https://bit.ly/3b9q6JQ

[2] A. Halfpenny and F. Kihm, "Rainflow cycle counting and acoustic fatigue analysis techniques for random loading," in 10th International Conference on Recent Advances in Structural Dynamics (RASD), Southampton, England, 2010, pp. 12-14.

[3] M. Yoon, K. Kim, J. E. Oh, S. B. Lee, K. Boo, and H. Kim, “The prediction of dynamic fatigue life of multi-axial loaded system," Journal of Mechanical Science and Technology, vol. 29, no. 1, pp. 79-83, 2015. doi: https://doi.org/10.1007/s12206-014-1212-1

[4] J.-B. Park and C. Y. Song, "Fatigue damage model comparison with formulated tri-modal spectrum loadings under stationary Gaussian random processes," Ocean Engineering, vol. 105, pp. 72-82, 2015. doi: https://doi.org/10.1016/j.oceaneng.2015.05.039

[5] J. D. Wu, Y. C. Luo, and H. Y. Lin, "Experimental and finite element analysis of vibrations of a rotating annular plates," Journal of Advances in Technology and Engineering Research, vol. 3, no. 6, pp. 235243, 2017. doi: https://doi.org/10.20474/jater-3.6.1

[6] J. P. Quigley, Y.-L. Lee, and L. Wang, "Review and assessment of frequency-based fatigue damage models," SAE International Journal of Materials and Manufacturing, vol. 9, no. 3, pp. 565-577, 2016. doi: https://doi.org/10.4271/2016-01-0369

[7] F. H. A. Suhadak, K. A. Zakaria, M. B. Ali, and M. A. Yusuff, “Fatigue damage simulation of automobile steering knuckle subjected to variable amplitude loading," International Journal of Technology and En- 
gineering Studies, vol. 3, no. 6, pp. 245-252, 2017. doi: https://doi. org/10.20469/ijtes.3.40004-6

[8] H. S. Jung, K. S. Kim, J. S. Kim, and S. W. Lee, "Fatigue life evaluation in frequency domain of aircraft equipment exposed to random vibration," Journal of the Korean Society for Aeronautical \& Space Sciences, vol. 45, no. 8, pp. 627-638, 2017. doi: https://doi.org/10.5139/jksas. 2017.45.8.627

[9] G.-W. Kim and K.-S. Shin, "The effect on fatigue life for dynamic behavior of external fuel tank horizontal fin," Journal of the Korean Society for Aeronautical \& Space Sciences, vol. 40, no. 3, pp. 209-214, 2012. doi: https://doi.org/10.5139/jksas.2012.40.3.209

[10] W. Hu, Z. Liu, D. Liu, and X. Hai, "Fatigue failure analysis of high speed train gearbox housings," Engineering Failure Analysis, vol. 73, pp. 5771, 2017. doi: https://doi.org/10.1016/j.engfailanal.2016.12.008

[11] Y. Morokuma, Y. Kamkoshi, S. Nishida, and I. Shohji, "Finite element method analysis of densification process of sintered steel for automobile in cold forging," International Journal of Technology and Engineering Studies, vol. 5, no. 1, pp. 30-36, 2019. doi: https://dx.doi. org/10.20469/ijtes.5.10005-1

[12] J. Xia, G. Li, B. Li, L. Cheng, and B. Zhou, "Fatigue life prediction of package-on-package stacking assembly under random vibration loading," Microelectronics Reliability, vol. 71, pp. 111-118, 2017. doi: https://doi.org/10.1016/j.microrel.2017.03.005

[13] A. Niesłony and M. Böhm, "Frequency-domain fatigue life estimation with mean stress correction," International Journal of Fatigue, vol. 91, pp. 373-381, 2016. doi: https://doi.org/10.1016/j.ijfatigue.2016.02. 031

[14] Z. Li and A. Ince, “'A unified frequency domain fatigue damage modeling approach for random-on-random spectrum," International Journal of Fatigue, vol. 124, pp. 123-137, 2019. doi: https://doi.org/10. 1016/j.ijfatigue.2019.02.032

[15] N. Fouchier, C. Nadot-Martin, E. Conrado, A. Bernasconi, and S. Castagnet, "Fatigue life assessment of a short fibre reinforced thermoplastic at high temperature using a through process modelling in a viscoelastic framework," International Journal of Fatigue, vol. 124, pp. 236-244, 2019. doi: https://doi.org/10.1016/j.ijfatigue.2019.03. 001

[16] Z. Wu, J. Liang, M. Fu, G. Fang, and Z. Zhou, "Study of random fatigue behavior of $\mathrm{C} / \mathrm{SiC}$ composite thin-wall plates," International Journal of Fatigue, vol. 116, pp. 553-561, 2018. doi: https://doi.org/ 10.1016/j.ijfatigue.2018.07.001

[17] A. Niesłony, M. Růžička, J. Papuga, A. Hodr, M. Balda, and J. Svoboda, "Fatigue life prediction for broad-band multiaxial loading with various PSD curve shapes," International Journal of Fatigue, vol. 44, pp. 74-88, 2012. doi: https://doi.org/10.1016/j.ijfatigue.2012.05.014
[18] Y. Li, Y. Zhang, and D. Kennedy, "Random vibration analysis of axially compressed cylindrical shells under turbulent boundary layer in a symplectic system," Journal of Sound and Vibration, vol. 406, pp. 161-180, 2017. doi: https://doi.org/10.1016/j.jsv.2017.06.018

[19] Y. Kong, S. Abdullah, D. Schramm, M. Omar, S. Haris, and T. Bruckmann, "Mission profiling of road data measurement for coil spring fatigue life," Measurement, vol. 107, pp. 99-110, 2017. doi: https: //doi.org/10.1016/j.measuremnt.2017.05.011

[20] V. P. Kos, J. Slavič, and M. Boltežar, "Fatigue damage for sweep-sine and random accelerated vibration testing," Advances in Mechanical Engineering, vol. 7, no. 2, p. 340545, 2014. doi: https://doi.org/10. $1155 / 2014 / 340545$

[21] D. Benasciutti and R. Tovo, "Comparison of spectral methods for fatigue analysis of broad-band Gaussian random processes," Probabilistic Engineering Mechanics, vol. 21, no. 4, pp. 287-299, 2006. doi: https://doi.org/10.1016/j.probengmech.2005.10.003

[22] M. A. Miner, "Cumulative damage in fatigue," Journal of Applied Mechanics-Transactions of the Asme, vol. 12, no. 3, pp. 159-164, 1945.

[23] D. S. Steinberg, Vibration analysis for electronic equipment. Hoboken, NJ: John Wiley \& Sons, 2000.

[24] S. Vantadori, I. Iturrioz, and C. Ronchei, "Discussion on fatigue life estimation under multiaxial random loading: Comparison between time- and frequency-domain approach," Theoretical and Applied Fracture Mechanics, vol. 96, pp. 134-145, 2018. doi: https:// doi.org/10.1016/j.tafmec.2018.02.009

[25] J. Kim, J-C. Yoon, and B.-S. Kang, "Finite element analysis and modeling of structure with bolted joints," Applied Mathematical Modelling, vol. 31, no. 5, pp. 895-911, 2007. doi: https://doi.org/10.1016/j. apm.2006.03.020

[26] S. Arabi, B. Shafei, and B. M. Phares, "Fatigue analysis of sign-support structures during transportation under road-induced excitations," Engineering Structures, vol. 164, pp. 305-315, 2018. doi: https://doi. org/10.1016/j.engstruct.2018.02.031

[27] Y. Ma, C. Han, and X. Qu, "Fatigue assessment method of marine structures subjected to two Gaussian random loads," Ocean Engineering, vol. 165, pp. 107-122, 2018. doi: https://doi.org/10.1016/ j.oceaneng.2018.07.033

[28] C. Lu, J. Nieto, I. Puy, J. Melendez, and J. Martínez-Esnaola, "Fatigue prediction of rail welded joints," International Journal of Fatigue, vol. 113, pp. 78-87, 2018. doi: https://doi.org/10.1016/j.ijfatigue.2018. 03.038 